\title{
O mito e seu valor pedagógico sob o olhar de licenciandos em pedagogia
}

\author{
The myth and its pedagogical value under the eyes of pedagogy \\ graduation students
}

Daniel Cardoso Alves

Resumo: A predominância da ausência de linguagem simbólica no contexto atual, inclusive, no que concerne à compreensão do próprio homem, incide na invisibilidade da função educativa do mito. Diante dessa hipótese, este artigo tem como objetivo compreender, no contexto do curso de Licenciatura em Pedagogia da Faculdade de Educação da Universidade do Estado de Minas Gerais, Campus Universitário de Belo Horizonte (FaE/UEMG-CBH), o lugar que o mito ocupa no processo de ensino e de aprendizagem dos anos elementares. Ancora-se em teóricos clássicos da Filosofia e Educação, como Félix Guattari, Friedrich Hegel, Gilles Deleuze, Paulo Freire e Platão, bem como, em mitólogos contemporâneos, a exemplo de Joseph Campbell, Mircea Eliade e Carl Jung, na tentativa de compreender o mito como essencial para o despertar da consciência humana. A revisão bibliográfica e a pesquisa de campo foram os instrumentos metodológicos adotados. Dentre os resultados, constatamos que os discursos dos sujeitos acerca da relação entre mito e educação, bem como, suas concepções, não se traduzem nas respostas desses mesmos sujeitos no que concerne à efetiva configuração do mito nos anos escolares.

Palavras-chave: Despertar. Função educativa. Mito. Pedagogia.

Abstract: The predominance of the absence of symbolic language in the current context, including, regarding the understanding of man himself, affects the invisibility of the educational function of the myth. Given this hypothesis, this article aims to understand, in the context of the Pedagogy Degree course at the Faculty of Education of the University of the State of Minas Gerais, Belo Horizonte University Campus (FaE / UEMG$\mathrm{CBH}$ ), the place that the myth occupies in the teaching and learning process of elementary years. It is anchored in classical theorists of Philosophy and Education, such as Félix Guattari, Friedrich Hegel, Gilles Deleuze, Paulo Freire and Plato, as well as in contemporary mythologists, such as Joseph Campbell, Mircea Eliade and Carl Jung, in an attempt to understand the myth as essential to the awakening of human consciousness. The bibliographic review and field research were the methodological instruments adopted. Among the results, we found that the subjects' speeches about the relationship between myth and education, as well as their conceptions, do not translate into the answers of these same subjects regarding the effective configuration of the myth in school years.

Keywords: Awakening. Educational function. Myth. Pedagogy.

El mito y su valor pedagógico bajo la mirada de los licenciantes de pedagogía

Resumen: El predominio de la ausencia de lenguaje simbólico en el contexto actual, incluido, en lo que respecta a la comprensión del hombre mismo, incide en la invisibilidad de la función educativa del mito. Dada esta hipótesis, este artículo tiene como objetivo comprender, en el contexto del curso de Grado en Pedagogía de la Facultad de Educación de la Universidad del Estado de Minas Gerais, Campus Universitario de Belo Horizonte (FaE / UEMG-CBH), el lugar donde el mito ocupa en el proceso de enseñanza 
y aprendizaje de los años elementales. Está anclada en teóricos clásicos de la filosofía y la educación, como Félix Guattari, Friedrich Hegel, Gilles Deleuze, Paulo Freire y Platón, así como en mitólogos contemporáneos, como Joseph Campbell, Mircea Eliade y Carl Jung, en un intento de comprender el mito como esencial para el despertar de la conciencia humana. La revisión bibliográfica y la investigación de campo fueron los instrumentos metodológicos adoptados. Entre los resultados, encontramos que los discursos de los sujetos sobre la relación entre mito y educación, así como sus concepciones, no se traducen en las respuestas de estos mismos sujetos sobre la configuración efectiva del mito en los años escolares.

Palabras clave: Despertar. Función educativa. Mito Pedagogía

\section{Introdução}

Este artigo tem como objetivo geral compreender, no contexto de um curso de Licenciatura em Pedagogia, o lugar que o mito ocupa no processo de ensino e de aprendizagem vivenciado pelos estudantes desse curso nos anos elementares da educação básica. Para tanto, valendo-se de uma abordagem metodológica qualitativa (BOGDAN; BIKLEN, 1994), serão investigadas e, ao mesmo tempo, relacionadas as concepções que os sujeitos da pesquisa têm sobre mito e educação, bem como, será apreendido o valor pedagógico que esses sujeitos atribuem ao mito ao longo dos seus diferentes anos escolares.

A reflexão sobre o lugar que o mito ocupa no processo educativo a partir da análise do seu valor para licenciandos em Pedagogia revela-se como uma necessidade latente, sobretudo, quando se volta o olhar para um momento histórico em que os mitos, dada a popularização conceitual equivocada e genérica a eles conferida, são reduzidos a narrativas fantásticas e curiosidades, perdendo o significado profundo de explicação da vida humana.

A predominância da ausência de linguagem simbólica no contexto atual, inclusive, no que concerne à compreensão do próprio homem, incide na invisibilidade da função educativa do mito, termo que, etimologicamente, tem origem no grego mythós, que diz respeito a discurso, mensagem, palavra e se traduz no latim como mutus, ou seja, mudo, aquele que silencia. A origem desse termo está, assim, associada com mensagem, porém, não uma mensagem explícita, mas aquela que exige um aprofundamento para o seu entendimento. Nesse sentido, os mitos são pedagógicos e, em geral, explica 
m como algo nasceu, nascimento este que não se resume ao plano físico, pois, diversas são as suas formas, dentre elas, o constante refazer-se dos novos patamares de consciência.

$\mathrm{Na}$ atualidade, em que o pensamento humano se caracteriza pelo imediatismo e tecnicismo, são muitas as interpretações acerca do mito, as quais, em sua maioria, associam-se a invenções populares fantásticas com a finalidade única de justificar tradições e/ou, intencionalmente, impor ideologias. A sua concepção como narrativa de caráter simbólico relacionada a uma cultura, ainda que fundamentada classicamente em Platão, é argumento de exceção na contemporaneidade, inclusive no meio acadêmico.

Poucas são as vozes, na atualidade, que concebem o mito associado à teoria das ideias de Platão, o qual defendia, em seus diálogos filosóficos presentes na obra "A República", a existência de dois planos, o ideal ou metafísico e o real ou físico. Conceber o mito pelo viés da teoria das ideias de Platão, significa compreendê-lo como arquétipo, um modelo a ser seguido. $O$ primeiro plano, segundo essa teoria, equivale ao lugar onde todas as coisas nascem, o ideal; o segundo, os reflexos do primeiro ou, simbolicamente falando, corresponde ao mundo das sombras, o real. No plano real, concreto, para Platão, não existe nada que não tenha se originado do plano das ideias, por sua vez, a evolução do mundo real segue o trajeto em direção ao ideal que o gerou. Os mitos seriam, assim, os rastros que permitiriam o movimento em direção ao ideal.

De acordo com a citada teoria, a evolução dos seres consiste em cada vez mais se aproximar do ideal, onde estão os modelos de tudo o que existe no plano real. O mito, nesse sentido, apresenta-se como projeção do mundo ideal para o mundo concreto, em que os modelos, as ideias perfeitas, podem alcançar a realidade concreta, conduzindo os seres humanos à sua completude. Em último, o mito, com roupagens culturais e vestimentas do contexto que the deu origem, é um modelo de como o ser humano galga degraus para a sua evolução, visando atingir um ideal, de fato, humano.

Contudo, é perceptível a carência coletiva de mitos pela qual passa a nossa civilização, que, em grande medida, acredita que pouco temos a aprender com eles, ainda que os problemas essenciais e fundamentais da vida tenham 
sido sempre os mesmos. Por isso, a importância de se refletir, pelo viés da teoria das ideias de Platão, o mito como um abstrato universal e simbólico, haja vista que, tudo que é simbólico carrega consigo uma possibilidade de comunicação.

Portanto, a hipótese que sustenta este artigo é a de que a educação formal tem, cada vez mais, privilegiado a escolarização, numa perspectiva técnica, em detrimento da formação dos valores humanos, pelo que, o mito, como símbolo das questões fundamentais da vida, cuja compreensão se expressa nas entrelinhas, vem sendo silenciado no processo de ensino e de aprendizagem, já que é reduzido a mera narrativa fantástica de pouca significância para a formação do sujeito. Dada a predominância de um processo educativo centrado na alfabetização no sentido restrito do domínio do sistema "alfabético-ortográfico" e da "aprendizagem do ler e do escrever" (SOARES; FRADE et. al., 2014), o mito raramente configura-se, no processo de ensino e de aprendizagem, como uma possibilidade para o sujeito alcançar novos patamares de consciência.

Este artigo estrutura-se em cinco seções. A primeira refere-se a esta introdução. Em seguida apresentamos o percurso metodológico adotado para o alcance do objetivo proposto. Na terceira, dialogamos com teóricos clássicos, bem como, com mitólogos contemporâneos na tentativa de conciliarmos a compreensão do mito como essencial para o despertar da consciência humana. A quarta seção diz respeito ao que os sujeitos da pesquisa, licenciandos em Pedagogia, pensam sobre mito e educação, as relações entre ambos e como o mito se configurou nos seus anos de formação escolar. Com as considerações finais, são tecidos alguns desfechos em relação à pesquisa empírica empreendida em sua correlação com a teoria em que se sustenta o estudo.

\section{Percurso metodológico}

Para compreendermos, no contexto da educação formal, o lugar que o mito ocupa no processo de ensino e de aprendizagem, adotamos como estratégia de pesquisa o "estudo de caso" que, para Trivinõs (1992) e Yin (2005), vem sendo frequente em pesquisas educacionais, dada a relevância qualitativa que essa estratégia assume no ramo das Ciências Humanas e Sociais. Nas 
palavras de Triviños (1992, p. 133), "o estudo de caso é uma categoria de pesquisa cujo objeto é uma unidade que se analisa profundamente", unidade esta que pode ser entendida como um indivíduo, um grupo, uma instituição, uma escola, um território, um lugar ou inúmeras outras possibilidades de casos.

O estudo de caso, nesse sentido, é uma estratégia de pesquisa que possibilita ao pesquisador debruçar-se exaustivamente sobre as singularidades da totalidade investigada. Essa profundidade exaustiva do pesquisador sobre o objeto de estudo de forma a explorá-lo ampla e detalhadamente, de acordo com Gil (2008, p. 57-58), é uma "[...] tarefa praticamente impossível mediante os outros tipos de delineamentos considerados", por isso, é importante destacar: primeiro, que essa caracterização singular do objeto, não significa a inexistência de similaridades com outros casos, mas centra-se no aspecto de que o interesse é que lhe dá a característica de distinto, ou seja, "o interesse incide naquilo que ele tem de único, de particular, mesmo que posteriormente venham ficar evidentes certas semelhanças com outros casos ou situações" (LUDKE; ANDRÉ, 1986, p. 17); segundo, que dada a flexibilidade metodológica admitida para estudos de casos, "um bom estudo de caso constitui tarefa difícil de realizar" (GIL, 2008, p. 59).

O curso de licenciatura em Pedagogia da FaE/UEMG-CBH, especificamente, os núcleos formativos $1 \mathrm{C}$ e $1 \mathrm{E}$, correspondente aos turnos vespertino e noturno, é o caso proposto neste estudo, de natureza qualitativa (BOGDAN; BIKLEN, 1994), cuja escolha cumpre e é coerente com esta proposta metodológica, a qual se ancora na "necessidade de um contato estreito e prolongado do pesquisador com a situação ou objeto pesquisado" (ANDRÉ, 1984, p. 53). No caso em análise, o pesquisador atende a esse requisito.

O percurso metodológico constituiu-se dos procedimentos revisão bibliográfica e pesquisa de campo, adotando-se como instrumento de pesquisa o questionário, estruturado de três questões abertas abordando os sentidos e significados dos sujeitos sobre suas concepções sobre mito e educação, bem como, o valor pedagógico do mito nos seus diferentes anos escolares.

A técnica utilizada para a categorização, sistematização e interpretação das respostas dos sujeitos, foi a "análise de conteúdo" que, segundo Bardin 
(1991), possibilita a apreensão da multiplicidade dos significados impressos nas respostas dos sujeitos sociais da pesquisa, preenchendo lacunas importantes para a maior compreensão da temática em estudo.

Os questionários foram aplicados entre os dias 22 de abril e 09 de maio de 2019 nos núcleos formativos 1E e 1C, respectivamente, durante as aulas da disciplina Estudos Filosóficos - Sociedade e Educação, que tem como ementa: Papel e significado da Filosofia; Educação e formação do educador; A infância como objeto da pedagogia.

Para preservar a identidade dos sujeitos participantes da pesquisa, adotou-se como estratégia a não identificação, pelo que, as respostas referentes aos estudantes do núcleo formativo $1 \mathrm{C}$ e do núcleo formativo $1 \mathrm{E}$ serão identificadas, respectivamente, como C1 a C33 e E1 a E33, considerando que participaram da pesquisa 66 (sessenta e seis) estudantes, sendo 33 (trinta e três) de cada núcleo formativo.

\section{A imprescindibilidade da mitologia para o pensamento filosófico}

À Filosofia, enquanto questionadora da sua própria existência, compete, por excelência, experimentar o retorno à tradição, porém, numa perspectiva de buscar a si mesma, centrando-se, para tanto, na sua essência, o que significa dialogar com a tradição, ou seja, não meramente uma reprodução histórica do passado (HEIDEGGER, 2009), visto que, "a filosofia é devir, não história; ela é coexistência de planos, não sucessão de sistemas" (DELEUZE; GUATTARI, 1992, p. 58-59).

Esse diálogo com o passado precede, perpassa e ultrapassa a compreensão das controvérsias existentes entre o nascer filosófico e a sua passagem de mito à razão, fazendo-se necessária uma abordagem sobre as suas definições, os seus precursores e o processo de laicização ao longo da sua trajetória de consolidação. Abordagem esta, que requer a (des)construção do esvaziamento do seu significado ao longo dos tempos.

Nesse sentido, refletir sobre a história do pensamento filosófico, cujo nascimento é atribuído aos filósofos pré-socráticos, ou seja, àqueles anteriores a Sócrates, considerando que foram eles os primeiros a não mais explicarem a 
realidade pautados numa consciência ingênua ${ }^{1}$, uma vez que, pretendiam com essa atitude uma autonomia de consciência para a explicação do real, baseados no recurso da linguagem, um recurso racional, desconstruindo as consciências ingênuas e empenhando-se em encontrar uma forma de pensamento mais crítica, perpassada pela dupla atitude de aproximação e distanciamento daquilo que Ihe causa espanto e admiração, esta, para Platão, principal discípulo de Sócrates, de acordo com Aranha (1993), a primeira virtude filosófica.

Ultrapassar a consciência ingênua, no contexto de nascimento do pensamento filosófico, retrata as controvérsias sobre a passagem do mito à razão, sendo evidente, por exemplo, que filósofos pertencentes à corrente do pensamento positivista, como o francês Augusto Comte, defendessem o abandono de toda e qualquer forma de explicação mítica e religiosa sobre a evolução da humanidade (ARANHA, 1993).

Consoante ao pensamento positivista, mas na base do nascimento da Filosofia, filósofos do século VI a. C., integrantes da escola jônica, tais como Tales de Mileto, ao qual se atribui o início, ainda de forma tênue, do pensamento filosófico-científico, demonstravam tamanha insatisfação com o fato de o pensamento mítico ser a única forma de explicação da realidade, motivo pelo qual, romperam abruptamente com a mitologia nesse aspecto, pois, defendiam que o pensamento filosófico surgia da superioridade da razão em relação ao mito. Para os jônicos, a realidade das coisas não poderia derivar de uma explicação misteriosa e sobrenatural.

Controversamente, outros estudiosos, representados por filósofos como Platão, da escola itálica, e Pitágoras, a este último é atribuída a invenção da palavra Filosofia, entendiam que tal passagem do mito (palavra de origem grega mythós, que significa narrar algo para alguém) à razão (palavra de origem grega logos, que significa discurso racional) ocorreu de forma paulatina, defendendo que a Filosofia, compreendida como um processo de busca pela sabedoria,

\footnotetext{
${ }^{1}$ Freire (1967, p. 59): "Se caracteriza, entre outros aspectos, pela simplicidade na interpretação dos problemas. Pela tendência a julgar que o tempo melhor foi o tempo passado. Pela subestimação do homem comum. Por uma forte inclinação ao gregarismo, característico da massificação. Pela impermeabilidade à investigação, a que corresponde um gosto acentuado pelas explicações fabulosas. Pela fragilidade na argumentação. Por forte teor de emocionalidade. Pela prática não propriamente do diálogo, mas da polêmica. Pelas explicações mágicas".
} 
nasceu do interior do pensamento mítico, ou seja, da criticização ${ }^{2}$ de uma forma de pensar que prevalecia, uma vez que, os pressupostos mitológicos, por se referirem à primeira leitura do mundo, eram necessários para a compreensão racional de tudo, até mesmo quando se pretendia refutá-los. Nas palavras do mitólogo Campbeell (1949),A função primaria da mitologia e dos ritos de passagem sempre foi a de fornecer os símbolos que levam o espirito humano avançar, opondo-se aquelas outras fantasias humanas constantes que tendem a leva-lo para trás. [...] Mantemo-nos ligados a imagens não exorcizadas da nossa infância, razão para a qual não nos inclinamos a fazer passagens necessárias para a vida adulta (p. 21-22). Essa compreensão acerca do mito encontra base teórica na teoria das ideias, exibida na República por Platão (1962), em que, para ele, o mundo sensível (real) é antes inteligível (ideal). Partindo dessa premissa, Platão desenvolve a sua teoria defendendo que, dado o constante movimento do mundo real, a apreensão das suas essências se dá pelo desvendar do mundo ideal, onde a realidade apresenta-se desvelada em suas essências e, portanto, imutáveis e permanentes, servindo de modelos, arquétipos a serem seguidos no mundo real como forma de se atingir um ideal inerente ao mundo inteligível. $\mathrm{Na}$ abordagem das diferentes etapas que comprovam o conhecimento verdadeiro e a existência dos dois mundos ou realidades, o sensível e o inteligível, Platão se apoia, ontologicamente, na alegoria da caverna, que se constitui como um trilhar para o acesso ao conhecimento verdadeiro, equivalente aos universais do mundo das ideias. Nessa mesma direção de pensamento, o psicanalista Jung (1942), entende queOs arquétipos não são apenas impregnações de experiências típicas, incessantemente repetidas, mas também se comportam empiricamente como forças ou tendências à repetição das mesmas experiências. Cada vez que um arquétipo aparece em sonho, na fantasia ou na vida, ele traz consigo uma "influência" específica ou uma força que lhe confere um efeito numinoso e fascinante ou impele à ação (p. 109).Corroborando com o entendimento da

\footnotetext{
${ }^{2}$ Freire (1967, p. 59): A criticidade para nós implica na apropriação crescente pelo homem de sua posição no contexto. Implica na sua inserção, na sua integração, na representação objetiva da realidade. Daí a conscientização ser o desenvolvimento da tomada de consciência. Não será, por isso mesmo, algo apenas resultante das modificações econômicas, por grandes e importantes que sejam. A criticidade, como a entendemos, há de resultar de trabalho pedagógico crítico, apoiado em condições históricas propícias.
} 
escola itálica, Marcondes (2007), considera que, o movimento em direção ao pensamento racional não representou uma ruptura com o mitológico, este apenas investiu-se de uma característica de tradição cultural, não sendo mais a única verdade das coisas. Esse movimento, para Marcondes (2007), seria inevitável diante de vários fatores contextuais, dentre os quais: o declínio da civilização micênico-cretense na Grécia, a alteração do regime político de monárquico divino para aristocrático militar, o advento de uma economia agrícola, o poderio das tribos dóricas sobre o território grego, o surgimento das cidades-Estado (as pólis), as invenções da escrita e do calendário e o incentivo à participação social ativa na vida política, além das atividades comerciais e mercantis que se intensificavam, ao mesmo tempo que, a influência religiosa sobre a vida dos gregos reduzia-se cada vez mais.

Diante desses diversos fatores, o pensamento mítico e religioso era insuficiente para a compreensão da nova realidade que se apresentava, a qual, inclusive, contradizia as explicações que até então prevaleciam, sobretudo, com os novos contatos, propiciados pelas viagens marítimas, com culturas diferentes, resultando na desmistificação que se tinha de outras realidades desconhecidas. Esse contexto efervescente de novas ideias, descredenciou a verdade inquestionável do mito centrada na autoridade que a proferia, pelo que, assumiu um conceito cultural, afetivo e imaginativo sobre a realidade e a vida humana.

De acordo com Chaui (1995), o mito, ainda que tenha precedido à Filosofia na tentativa de expressar o saber sobre a realidade, opõe-se, à primeira vista, dos princípios filosóficos, uma vez que, o pensamento filosófico não se finda em explicações divinas, incompreensíveis e ingênuas da realidade, pelo contrário, ele ultrapassa narrativas sobrenaturais e inquestionáveis, as quais, como já foi dito, começaram a perder o seu poder unilateral de explicação da realidade das coisas, em fins do século VII e início do século VI a. C., quando o pensamento filosófico encontrou as condições favoráveis para o seu nascimento.

Entretanto, apesar das controvérsias acerca da transição entre mito e razão, ambas são filosoficamente aceitas, no que se refere à mudança na forma de compreensão da realidade. Dessa forma, "os mitos são mais do que uma simples narrativa; são a maneira pela qual, através das palavras, os seres 
humanos organizam a realidade e a interpretam" (CHAUI, 1995, p. 173), pelo que, na atualidade, [...] afirma-se que a Filosofia, percebendo as contradições e limitações dos mitos, foi reformulando e racionalizando as narrativas míticas, transformando-as numa outra coisa, numa explicação inteiramente nova e diferente (CHAUI, 1995, p. 34). Sobre esse aspecto, Chaui (1995) entende que as contradições mitológicas passaram por algumas reformulações que as tornaram mais racionais, aproximando-as de um conceito de Filosofia totalizante, coerente, racional, universal, lógica e, principalmente, empenhada na busca da verdade através de um constante processo de repensar-se.

Para a citada autora, outra controvérsia permeia o nascimento da Filosofia: a supervalorização grega. Os gregos ao definirem a origem da Filosofia como, unicamente, produto de um "milagre grego", cometeram evidente exagero nessa definição, pois ignoraram as outras culturas, as quais contribuíram de forma significativa para a definição de uma Filosofia, que se consolidou ao longo do tempo, conceitualmente, como a busca, o entender, e o explorar dos porquês das coisas, dos fenômenos e das ações.

Apreende-se, assim, que de uma origem mitológica dual, para alguns abrupta, para outros processual, movimentando em direção a um saber racional, o pensamento filosófico com o objetivo de buscar explicações para as coisas e, ao mesmo tempo, afirmar-se como um movimento de busca pela verdade conceitual das coisas, integra e, jamais, separa ou segrega, ou seja, não há que se pensar o mito como pólo oposto da razão, pois foi do movimento mito-razão, por exemplo, que poetas como Homero (autor da obra llíada e Odisseia) e Hesíodo, anteriores ao século VI a. C., inseriram a reflexão sobre a origem do mundo (cosmogonia) e dos deuses (teogonia) de forma mitológica, possibilitando o nascimento da Filosofia, cujos filósofos pré-socráticos empenhados na sistematização racional da origem do universo, consolidaram uma nova forma de pensar, que denominaram cosmologia, a Filosofia nascente.

No que concerne à concepção de mito associado com criação, o mitólogo Eliade (1972), esclarece queO mito conta uma história sagrada; ele relata um acontecimento ocorrido no tempo primordial, o tempo fabuloso do "princípio". Em outros termos, o mito narra como, graças às façanhas dos Entes Sobrenaturais, 
uma realidade passou a existir, seja uma realidade total, o Cosmo, ou apenas um fragmento: uma ilha, uma espécie vegetal, um comportamento humano, uma instituição. É sempre, portanto, a narrativa de uma "criação": ele relata de que modo algo foi produzido e começou a ser (p.11).Esse movimento demonstrou que a mudança na forma de interpretar a realidade foi processual, reforçando a ideia de que o mito nunca deixou de fazer parte do conhecimento filosófico, apenas deixou de ser objeto de via única de explicação da origem das coisas, as quais passaram a ser questionadas e, assim, repensadas em sua totalidade complexa e dialética. Não houve, portanto, uma ruptura abrupta entre mito e razão, mas sim, uma série de acontecimentos que influenciaram o pensamento do homem mítico.

Com a consolidação do pensamento filosófico, o homem passou a não mais se limitar a explicações aparentes da realidade, mas a aprofundar-se nessas explicações até então aparentes e refletir de forma lógica e coerente sobre o seu próprio pensar e as verdades postas. Assim, a reflexão humana, com a Filosofia, adquiriu características de rigor metodológico, crítico, relacional, centrada no todo e em tudo, e necessária para a fuga do pensamento estático e imediatista, sem as quais não se alcançaria os fundamentos e os princípios que orientam a própria consciência humana.

Portanto, apesar de aparentemente díspares, a mitologia e a Filosofia têm muito em comum, dada a busca pela explicação dos fenômenos e das coisas da vida a partir do espanto do homem com o mundo. Somente quando os mitos se tornaram insuficientes para explicar os fenômenos de um mundo que começava a ser desvendado de modo mais amplo, foi que se tornou possível o nascimento de novos patamares de consciência.

A mitologia apresenta-se, pelo exposto, como essencial para o despertar da consciência humana e, portanto, imprescindível para o processo de ensino e de aprendizagem pautado numa educação que não se finda na escolarização. Pensar filosoficamente a educação é, antes, retomar o espírito originário do que é educação para, então, (re)defini-la e/ou aperfeiçoá-la, ultrapassando a visão meramente materialista apoiada numa supervalorização quantitativa que tende a reduzi-la a preço, ao mercado, e a insere num discurso de plano ainda muito 
horizontal e superficial. A educação, no seu sentido clássico de tornar o homem cada vez mais humano e, em alusão ao mito da caverna de Platão, de dar à luz, eduzir e trazer à tona o que há de melhor no sujeito, descortinando sombras e afastando a inércia, vem perdendo espaço para uma lógica que atua para reduzila à mera escolarização.

\section{A relação entre mito e educação infantil sob o ponto de vista de futuros pedagogos}

A pesquisa foi realizada entre os meses de abril e maio de 2019 durante as aulas da disciplina "Estudos Filosóficos - Sociedade e Educação", componente integrante do primeiro núcleo formativo do currículo do curso de licenciatura em Pedagogia da FaE/UEMG-CBH. Os sujeitos participantes, num total de 66 (sessenta e seis), constituíram-se de estudantes matriculados na citada disciplina e presentes no dia de aplicação do questionário, instrumento utilizado para a apreensão do que esses futuros pedagogos pensavam sobre a relação entre mito e educação, suas concepções e o lugar que o mito ocupou durante o percurso escolar na educação básica.

O critério de seleção adotado para a escolha dos sujeitos diz respeito ao fato de estarem no processo de transição da educação básica para a educação superior e no início da formação de professores da educação infantil. Essas duas condições foram importantes por permitirem análises do que pensam sujeitos, em processo de transição e em formação superior inconclusa/inicial, sobre o valor pedagógico do mito, suas concepções, relações com a educação e sua presença na educação básica, sem as barreiras do lapso temporal de formação escolar e, também, sem a consolidação da teoria acadêmica.

Os 66 (sessenta e seis) estudantes que participaram da pesquisa, distribuídos em 33 (trinta e três) por turno (vespertino e noturno). Esses estudantes, nos 20 (vinte) minutos finais da aula, foram convidados para responderem as 03 (três) questões abertas que compunham o questionário aberto: (1) Que lugar o Mito ocupa no processo de ensino e de aprendizagem? (2) Qual(is) sua(s) concepção(ões) sobre o Mito? (3) Como o Mito se configurou ao longo dos seus anos escolares? 
Assim, acerca do primeiro questionamento (1), 40\% (quarenta por cento) dos respondentes compreendem que o mito, no processo de ensino e de aprendizagem, possibilita o despertar da consciência crítica do aluno, explica a realidade, desvela consciências abstratas e significa o próprio ato de sair da ignorância, conforme se ilustra nos quatro relatos abaixo:O mito pode representar o indivíduo que ainda possui a consciência mágica, após o processo de ensino-aprendizado, esse indivíduo para de ver o mundo por meio de sombras e adquire uma consciência crítica (E1, 22/04/2019).

O mito ocupa um lugar primordial na relação ensino e de aprendizagem. Tendo premissa que o mito é uma narrativa com o objetivo de explicar a realidade, fenômenos, etc. Na relação ensino e de aprendizagem ele se faz presente a todo momento (E2, 22/04/2019).

O mito traz perspectivas que uma ideia concreta não nos mostra, podendo contribuir na reflexão do aluno, que busca refletir sobre concepções que não imaginava (C1, 09/05/2019).

O mito de Platão explica de forma metafórica a ignorância do ser humano e a forma como se dá a reversão desta situação e o processo de ensino e de aprendizagem é realmente este caminho percorrido (E3, 22/04/2019). Para 29\% (vinte e nove por cento) dos sujeitos, o mito explica a própria vida e a essência humana; simboliza a cultura, os costumes, os valores morais, de justiça, ética e respeito, bem como, os sentimentos humanos. Nas palavras dos sujeitos E4, C2, E5 e E6:Os mitos em suas muitas interpretações se relacionam com a humanidade e o entendimento do homem acerca de si, portanto, a concepção acerca do lugar ocupado pelo mito no processo de ensino e de aprendizagem se dá nessa linha de compreensão do homem sobre a sua essência (E4, 22/04/2019).

Traz a tona por meio de histórias o conceito sobre a vida, os costumes, os valores e sentimentos dos personagens para aquele que aprende através da história o seu modo de atuação no meio em que vive (C2, 09/05/2019).

O mito no processo de ensino e de aprendizagem é importante pois envolve história da cultura de uma sociedade, contribuindo para o enriquecimento cultural (C3, 09/05/2019).

O mito mostra e passa certos ensinamentos e realidades com certa preocupação com a moral, a justiça, etc (E6, 22/04/2019).

Entre 17\% (dezessete por cento) dos futuros pedagogos, o mito é um facilitador do processo de ensino e de aprendizagem, pois:Podem ajudar nas didáticas de ensino e de aprendizagem (C4, 09/05/2019).

Auxiliam no processo de aprender, escrever, interagir, dentre outros (E7, 22/04/2019). 
Além de fazer parte de um contexto histórico específico, pode contribuir para fazer paralelos/analogias que facilitem determinadas explicações (E8, 22/04/2019).

Se o mito for uma forma que o ser humano desenvolveu para explicar comportamentos e sentimentos humanos, acredito que ele pode ser uma forma de introduzir temáticas que podem causar certa estranheza ou aversão numa comunidade escolar que tenha resistência no tratamento de assuntos considerados proibidos ou considerados como tabus (E9, 22/04/2019). Por outro lado, $8 \%$ (oito por cento) dos respondentes vinculam o mito a um processo de ensino e de aprendizagem meramente lúdico, desprovido de criticidade, arraigado a um pensamento geracional fantasioso e mentiroso que representa uma barreira para o ensino escolar. Para os sujeitos E10, C5, E11 e E12, o mitoNo processo de ensino e de aprendizagem encontra-se na primeira formação consciente acerca do mundo e sua constituição. O mito seria uma proposição lúdica, sem caráter crítico, de apresentar a realidade (E10, 22/04/2019).

Considerando o mito como algo não comprovado, no processo de ensino e de aprendizagem ele colabora no incentivo a pesquisa, mostrando que é necessário embasamento para se discutir assuntos pedagógicos/acadêmicos e não se ater somente ao conhecimento de contos populares (C5, 09/05/2019).

Eu acredito que não deveria ocupar nenhum lugar, porém o mito está na história para fazer parte do processo de ensino e de aprendizagem (E11, 22/04/2019).

O mito acaba ocupando um lugar especial no processo de ensino e de aprendizagem, pois são muitas informações, experiências baseadas no senso comum e acaba de uma maneira ou de outra atrapalhando o processo. Ex: a famosa história de comer manga e tomar leite faz mal. Informação antiga passada de gerações (E12, 22/04/2019). Da totalidade dos respondentes, apenas $6 \%$ (seis por cento) entendem que o mito ocupa pouco ou nenhum espaço no processo de ensino e de aprendizagem, como depreende-se das seguintes respostas:Acredito que atualmente o mito não ocupa espaço no processo de ensino e de aprendizagem, sendo esquecido no meio do processo $(E 13,22 / 04 / 2019)$.

Não tenho conhecimento aprofundado sobre o assunto (C6, 09/05/2019).

No processo de ensino e de aprendizagem o mito ocupa pouco lugar, hoje em dia este processo busca atualizações didáticas que facilitem para o aluno a aprendizagem (E14, 22/04/2019). Dos excertos destacados, percebemos que a perspectiva contra hegemônica do mito na academia como algo de valor, 
cuja simbologia tem muito a ensinar, provoca a inquietação no sujeito para o alcance de novos patamares de consciência sobre a realidade, a vida e a sua existência humana, são ecoadas entre $87 \%$ (oitenta e sete por cento) dos licenciandos em Pedagogia da FaE/UEMG-CBH que, em seus discursos, inserem o mito no processo de ensino e de aprendizagem com perspectiva semelhante a essas poucas vozes. Ao fazerem essa relação entre o mito e o processo de ensino e de aprendizagem, ultrapassam a noção meramente escolarizadora da educação formal, centrada na alfabetização no seu sentido restrito (SOARES; FRADE et. al., 2014).

Com relação ao segundo questionamento (2), 55\% (cinquenta e cinco por cento) dos sujeitos, ou seja, a maioria, compreendem o mito como uma abstração universal que explica a origem, o nascimento, a criação de algo e/ou a aquisição de novos níveis de consciência. Essa compreensão se traduz nos discursos dos sujeitos C2, E15, E16 e C7:Mitos são histórias que remontam a um passado para trazerem a tona costumes, valores e sentimentos que remetem dos nossos valores atuais, a nossa própria história (C2, 09/05/2019).

É tentar explicar a origem dos homens, dos sentimentos e dos fenômenos naturais (E15, 22/04/2019).

Entendo o mito como uma alegoria, representação imagética de situações e personalidades reais. Mitos foram criados para explicarem o mundo, suas origens e seus acontecimentos (E16, 22/04/2019).

Mito é uma história criada para tentar explicar algo (C7, 09/05/2019). Entretanto, uma parcela considerável dos sujeitos, $29 \%$ (vinte e nove por cento), entendem o mito como uma invenção popular, fantástica e mentirosa para justificar tradições, sendo essa a concepção mais difundida na sociedade que, frequentemente, interpreta o mito como um antônimo da verdade. Dessa forma, o mito para os sujeitos E8, C8, E17, C9 e C10 constitui-se como:Histórias/narrativas fictícias (E8, 22/04/2019).

Algo que não pode ser provado ou mentira (C8, 09/05/2019).

Comparo o mito à consciência ingênua, de Paulo Freire, que trata-se da posição natural em que somos inseridos no processo de ensino e de aprendizagem, ausentes de criticidade, posicionamento, conhecimentos prévios e externos (E17, 22/04/2019). 
Na minha concepção o mito está presente desde os primórdios da civilização, buscando interpretar o passado. Nesse contexto, o mito é visto como uma espécie de conto (C9, 09/05/2019).

O mito referencia a algo ou alguém que não exista; que não é verdadeiro (C10, 09/05/2019). Enquanto 29\% (vinte e nove por cento) dos sujeitos concebem o mito como um conhecimento mentiroso, $11 \%$ (onze por cento) o entendem como verdades absolutas e inquestionáveis e $6 \%$ (seis por cento) não têm nenhuma concepção formada a seu respeito, como se apreende dos seguintes discursos:Portador de uma verdade acreditada de propósitos de ensinar (E7, 22/04/2019).

Mito também passa uma ideia de algo intocável, inquestionável e superior. Talvez antigo e irreal também. (E6, 22/04/2019).

São histórias contadas, que se tornam verdades, mas não há como comprová-las (C11, 09/05/2019).

Mito é algo consolidado nas sociedades em geral como algo de verdade absoluta (C12, 09/05/2019).

Eu não tenho muitas concepções (C13, 09/05/2019).

Ainda não tenho uma concepção concreta, não sei se é algo com relevância positiva ou negativa (C6, 09/05/2019). Esse questionamento trouxe à tona as principais definições que prevalecem acerca do mito na atualidade, dentre as quais, narrativa de caráter simbólico relacionada a uma dada cultura; fantasias populares tradicionalmente criadas e transmitidas pelas gerações; crenças indiscutíveis; e explicação simbólica do despertar da consciência. Contudo, o que chama a atenção é que, mesmo ainda em processo inicial de formação filosófico-pedagógica, os sujeitos, ao definirem, em sua maioria, o mito como algo de simbólico que leva à racionalização de como as coisas surgem e a própria natureza e a consciência humana se formam, rompem com a ideia vulgarizada que, historicamente, prevalece sobre o mito na sociedade.

Acerca do último questionamento (3), 66\% (sessenta e seis por cento) dos sujeitos responderam que tiveram algum tipo de contato com o mito nos conteúdos abordados nos anos escolares. Desses, $42 \%$ (quarenta e dois por cento) associaram a abordagem sobre mito com as obras de Monteiro Lobato, disciplinas de Filosofia, História, Literatura e Português e, principalmente, com a exploração do mito da caverna, como se transcreve:Logo nos meus primeiros anos escolares, logo após aprender a ler, ganhei uma coleção de Monteiro Lobato. Este foi 
meu primeiro contato com o universo mitológico e desde então me mantive interessada por ele (C15, 09/05/2019).

Tive algumas aulas de mito durante as aulas de Filosofia, Literatura e História, mas apenas foi aprofundado o mito da caverna durante as aulas de Filosofia (C14, 09/05/2019).

Me recordo de estudar sobre mitos ao ler textos sobre o assunto na disciplina de Português e Interpretação de Textos. Não me recordo de ter tido uma disciplina que aprofundou o assunto (E19, 22/04/2019).

Durante meus anos escolares tive curto contato com estudo de mitos, apenas no ensino médio estudei o mito da caverna de Platão nas aulas de Filosofia (E18, 22/04/2019).

Se deu através dos ensinamentos da matéria de História e que depois de certo entendimento percebi que muita coisa foi falada de forma equivocada (C16, 09/05/2019). Os outros $24 \%$ (vinte e quatro por cento) disseram que o contato com o mito no decorrer dos anos escolares foi superficial e de pouca significância. Segundo esses sujeitos, o mitoOcupou um pequeno espaço no processo de educação, talvez uma questão sem relevância. Me reporta a histórias infantis (C11, 09/05/2019).

O mito se configurou bem raro nos meus anos escolares, pois tive pouca matéria sobre o mesmo. Lembro que foi na $7^{a}$ para $8^{a}$ série e muito se falou sobre deuses, astros, heróis, etc. Não acredito que tenho muita base para falar sobre o mito (E11, 22/04/2019).

O mito durante meus anos escolares foi configurado como não tão relevante, por não ter sido algo tão abordado para discussão e reflexão (C17, 09/05/2019).

De uma maneira distante, pois convivi mais com lendas (C18, 09/05/2019).

$\mathrm{Na}$ verdade o mito foi pouco explorado nos meus anos escolares. Somente uma "pincelada" sobre a mitologia grega (E20, 22/04/2019). Todavia, um quantitativo expressivo da totalidade dos sujeitos, $34 \%$ (trinta e quatro por cento), afirmaram que não tiveram nenhum tipo de contato com o mito nos diferentes anos escolares. Os sujeitos E4, E9, C19, C20 e C21 descrevem essa invisibilidade sobre o mito nos anos escolares da seguinte forma:Não se configurou, se minha memória não me trai. Não tive tantas aulas de Filosofia e quando a mitologia grega entra em jogo, um imprevisto ocorreu - só não me recordo qual (E4, 22/04/2019).

Não me recordo de ter tido algum contato teórico com o mito. Durante minha formação escolar não me lembro de ter tratado 
do assunto, apesar de ter tido Filosofia na maior parte do meu ensino básico (E9, 22/04/2019).

Em meus anos escolares, o mito não foi muito abordado. Não foi mostrado nada muito além de folclore, etc (C19, 09/05/2019).

Não tive contato com nenhuma matéria que abordasse o tema (C20, 09/05/2019).

Não me lembro de ter tido qualquer influência ou alusão a este assunto nos meus anos escolares (C21, 09/05/2019). Os discursos obtidos com essa última questão reforçam a tese defendida neste artigo de que o sentido do mito, compreendido enquanto potente instrumento de transformação da consciência, vem sendo silenciado no processo de ensino e de aprendizagem nos anos elementares da educação formal, já que, quando o mito ganha visibilidade na escola, é reduzido a mera narrativa fantástica de pouca significância para a formação do sujeito, restringindo-se, na maioria das vezes, a poucos períodos escolares e ancorado exclusivamente na cultura grega abordada de forma ilustrativa e dissociada da sua importância para o despertar da consciência humana.

O fato da mitologia encontrar-se reduzida no ambiente escolar, associase a uma visão adultocêntrica que, segundo Kohan (2004), foi herdada da tradição filosófico-educacional ocidental que reduz o ser criança e todo o mundo que a cerca a uma etapa menos importante da vida (a infância).

\section{Considerações finais}

Com a pesquisa concluímos que, $87 \%$ (oitenta e sete por cento) dos estudantes de Pedagogia da FaE/UEMG-CBH percebem a relação entre o mito e o processo de ensino e de aprendizagem no decorrer dos seus anos escolares pelo viés de uma perspectiva de narrativa simbólico-cultural que conduz o aluno ao nascimento de novas consciências, 55\% (cinquenta e cinco por cento) o concebem à luz de Campbeell (1949), Eliade (1972) e Jung (1942), teóricos que sustentam a concepção defendida neste artigo, e 66\% (sessenta e seis por cento) recordam da presença do mito nos conteúdos ministrados durante a trajetória escolar. Esses percentuais demonstram que, provavelmente, a 
mitologia não será reduzida a mera narrativa fantástica nos anos elementares do ensino formal por esses sujeitos, futuros professores da educação infantil.

Todavia, incoerentemente, essa concepção de mitologia não se traduz nos discursos desses mesmos sujeitos no que concerne à efetiva configuração do mito nos anos escolares. Ou seja, 42\% (quarenta e dois por cento) afirmaram que o mito foi abordado como mera ficção lendária, restrito a atividades de práticas de leitura literária e/ou letramento histórico no seu sentido restrito; $24 \%$ (vinte e quatro por cento) entendem que o mito não foi explorado a contento nos seus anos escolares, sendo abordado de forma aligeirada, superficial e sem conexão com a realidade; e expressivos 34\% (trinta e quatro por cento) afirmaram que não tiveram nenhum tipo de contato com a mitologia em todos os anos escolares da educação básica.

Das análises dos discursos, também se constatou o que CHAUI (1995) chama de "supervalorização da cultura grega" na abordagem escolar da mitologia, uma vez que, foram recorrentes nas respostas dos sujeitos referências à mitologia grega, exclusivamente, ao "Mito da Caverna" e "Ícaro e Dédalo", o que infere dizer que, na educação básica, prevalece essa supervalorização da cultura grega em detrimento de outras culturas, bem como, a ancoragem em filósofos clássicos como Platão, o único citado pelos sujeitos.

Pelo exposto, o mito é tratado, efetivamente, no processo de ensino e de aprendizagem desenvolvido na educação básica, de forma muito semelhante à popularização equivocada do seu conceito, reduzido a narrativas fantásticas e curiosidades, desprovido de significado profundo de explicação da vida humana cedente de compreensão aprofundada.

Diante dessa constatação, ainda se faz necessária a compreensão de que mitos se vivem, eles são chaves que decifram nossa vida e aprender a usá-las pode auxiliar a nos edificarmos enquanto seres humanos. Parafraseando o poeta Fernando Pessoa: "O mito é o nada que é tudo. O mesmo sol que abre os céus é um mito brilhante e mudo - O corpo morto de Deus, Vivo e desnudo [...]" (PESSOA, 1934).

Portanto, os mitos nos ensinam a viver, com eles aprendemos. Os mitos são parte da nossa vida que, por ser inteiramente simbólica, tem uma 
possibilidade de comunicação. Nesse sentido, para além de um pensamento humano caracterizado pelo imediatismo e tecnicismo exacerbados, inclusive, sustentado em discursos políticos que pregam a pouca importância das humanidades no processo de escolarização e que prevalecem na cena sóciopolítica brasileira atual, é que o mito, enquanto despertar da consciência humana, se apresenta e revela-se imprescindível para o processo de ensino e de aprendizagem em quaisquer dos seus níveis.

Assim, apesar de haver uma carência coletiva concernente ao foco com que, efetivamente, é abordado o mito no âmbito escolar, devela esta pesquisa que aprendemos com os mitos, eles nos ensinam a viver e fazem parte da nossa vida que, por sua simbologia, tem uma capacidade comunicativa demandante de compreensão.

\section{Referências}

ANDRÉ, Marli Elisa Dalmazo Afonso de. Estudo de caso: seu potencial na educação. Cadernos de Pesquisa, 1984.

ARANHA, M. L. A. e MARTINS, M. H. P. Filosofando - introdução à Filosofia. 2. ed. São Paulo: Moderna, 1993.

BARDIN, L. Análise de Conteúdo. Lisboa, Portugal; Edições 70, LDA, 2009 (1991).

BOGDAN, R. C.; BIKLEN, S. K. Investigação Qualitativa em Educação - uma introdução à teoria e aos métodos. Porto: Porto Editora, 1994.

CAMPBELL, Joseph. $\mathbf{O}$ herói de mil faces. São Paulo: Cultrix/Pensamento, 2005 (1949).

CHAUI, Marilena. Convite à Filosofia. São Paulo: Ática, 1995.

DELEUZE, Gilles; GUATTARI, Félix. O que é a Filosofia? [Tradução de Bento Jr. E Alberto Alonso Muñoz]. Rio de Janeiro: Ed. 34, 1992.ELIADE, Mircea. Mito e realidade. São Paulo: Perspectiva, 1972.

FREIRE, Paulo. Educação como prática de liberdade. 3. ed. Rio de janeiro: Paz e Terra, 1979.

GIL, Antônio Carlos. Métodos e técnicas de pesquisa social. 6. ed. - São Paulo: Atlas, 2008.

HEGEL, G.W.F. Fenomenologia do Espírito. Trad. Paulo Meneses. Petrópolis, Vozes, 2003. 
HEIDEGGER, Martin. Que é isto, a Filosofia? Identidade e diferença. Tradução de Ernildo Stein. $2^{a}$ edição. Petrópolis: Vozes, São Paulo: Livraria Duas Cidades, 2009.

JUNG, Carl Gustav. O inconsciente pessoal e o inconsciente coletivo. Petrópolis: Vozes, 1942.

KOHAN, W.O. 2010. A infância, entre o humano e o inumano. In: R.L. GARCIA (ed.), Diálogos cotidianos. Petrópolis/Rio de Janeiro, FAPERJ, p. 195204.

LUDKE, Menga. André, Marli Elisa Dalmazo Afonso de. Pesquisa em educação: abordagens qualitativas. São Paulo: EPU, 1986.

MARCONDES, Danilo. Iniciação à história da Filosofia: dos pré-socráticos a Wittgenstein. 11. ed. rev. e ampl. Rio de Janeiro: Zahar, 2007.

PESSOA, Fernando. Mensagem. Lisboa: Parceria António Maria Pereira, 1934 (Lisboa: Ática, 10ª ed. 1972). - 25.

PLATÃO. A república. 8. ed. São Paulo: Atena, 1962.

SOARES, M. Alfabetização. In: FRADE, I. C. A. S; VAL, M. da G. C. G; BREGUNCI, M. das G. C. Glossário Ceale de termos de Alfabetização, leitura e escrita par educadores. Belo Horizonte, CEALE/Faculdade de Educação da UFMG. 2014. Disponível em: <http://www. ceale.fae.ufmg.br/app/webroot/glossarioceale/verbetes/alfabetização>. Acesso em: 18 abr. 2019.

TRIVINOS, A.N.S., 1992. Introdução à pesquisa em ciências sociais: a pesquisa qualitativa em educação, São Paulo. Atlas. YIN. R. K. Estudo de caso: planejamento e métodos. 3. ed. Porto Alegre: Bookman, 2005.

\section{Sobre os autores}

\section{Daniel Cardoso Alves}

dca.uemg@gmail.com

Mestre em Ciências Ambientais. Docente da Faculdade de Educação da Universidade do Estado de Minas Gerais, Belo Horizonte (FaE/UEMG-CBH), Departamento de Fundamentos Sócio-históricos e Filosóficos da Educação (DFSHFE). 